\title{
BALANÇO DA ADUBAÇÃO NITROGE NADA SÓLIDA E FLUIDA DE COBERTURA NA CULTURA DE MILHO, EM SISTEMA PLANTIO DIRETO NO TRIÂNGULO MINEIRO (MG) ${ }^{(1)}$
}

\author{
W. A. R. LARA CABEZAS(2), P. C. O. TRIVELIN ${ }^{(3)}$, \\ G. H. KONDÖRFER ${ }^{(4)} \&$ S. PEREIRA ${ }^{(5)}$
}

\begin{abstract}
RESUMO
Foi desenvolvido um experimento com as fontes uréia e uran aplicadas superficialmente ou incorporadas $(5-7 \mathrm{~cm})$ na cobertura nitrogenada de milho, no sistema plantio direto, com o objetivo de efetuar, na colheita, um balanço do $\mathrm{N}$-uréia $\left({ }^{15} \mathrm{~N}\right)$ e quantificar as perdas por volatilização de $\mathrm{N}-\mathrm{NH} \mathrm{H}_{3}$ nesses tratamentos, assi $\mathrm{m}$ como nos adicionais, testemunha e misturas de uréia $+\mathrm{KCl}$ (sólida) e uran $+\mathrm{KCl}$ (fluida), na formulação 6-0-9 $\left(\mathrm{N}-\mathrm{P}_{2} \mathrm{O}_{5}-\mathrm{K}_{2} \mathrm{O}\right)$, aplicadas somente em superfície. Os tratamentos ori gi naram-se de um fatorial $1+(2 \times 2)+2$, sendo a testemunha + o fatorial $2 \times 2$ (duas fontes; uréia e uran $x$ duas formas de localização) + dois tratamentos adicionais, misturas uréia $+\mathrm{KCl}$ (sólida) e uran $+\mathrm{KCl}$ (fluida), dispostos em blocos casualizados com quatro repetições. $\mathbf{O}$ ensaio foi realizado em Latossolo Vermelho-Escuro muito argi loso fase cerrado relevo plano, no Centro de Pesqui sa Novartis - Seeds do município de Uberlândia (MG). Cerca de $100 \mathrm{~kg} \mathrm{ha}^{-1}$ de $\mathrm{N}$ foram aplicados no estádio fenológico de seis a oito folhas. Após 26 dias da adubação, as perdas acumuladas de $\mathbf{N}-\mathrm{NH}_{3}$ nos tratamentos em superfície foram de 54, 41, 17 e 14\% do $\mathrm{N}$ aplicado, para uréia, uréia $+\mathrm{KCl}$, uran e uran $+\mathrm{KCl}$, respectivamente. Quando a uréia e o uran foram incorporados ao solo, as perdas acumuladas de $\mathrm{N}-\mathrm{NH}_{3}$ foram de 5,0 e 3,5\% do $\mathrm{N}$ aplicado, respectivamente. $\mathrm{Na}$ colheita, $\mathbf{O} \mathbf{N}$ da uréia absorvido pela planta (raízes + colmos + folhas + grãos) foi de $19,9 \mathrm{~kg} \mathrm{ha}^{-1}$ (20,8\% do $\mathrm{N}$ aplicado) e de $29,5 \mathrm{~kg} \mathrm{ha}^{-1}$ (29,5\% do $\mathrm{N}$ aplicado), quando aplicado na superfície e incorporado, respectivamente. $0 \mathrm{~N}$-uréia do uran absorvido pela planta foi de $11,4 \mathrm{~kg} \mathrm{ha}^{-1}$ (26,1\% do $\mathrm{N}$ aplicado) e de $11,7 \mathrm{~kg} \mathrm{ha}^{-1}$ (26,8\% do $\mathrm{N}$ aplicado), quando aplicado na superfície ou incorporado, respectivamente. $\mathrm{O}$ N da uréia imobilizado na camada
\end{abstract}

\footnotetext{
(1) Parte do trabalho apresentado no VI Encontro Nacional de Plantio Direto na Palha, Brasília, junho 1998. Recebido para publicação em dezembro de 1998 e aprovado em fevereiro de 2000.

(2) Professor Visitante do Instituto de Ciências Agrárias, Universidade Federal de Uberlândia - UFU, Caixa Postal 593, CEP 38406067 U berlândia (MG). Bolsista da CAPES.

(3) Professor do Centro de Energia Nuclear na Agricultura/USP. Caixa Postal 96, CEP 13400-970 Piracicaba (SP). Bolsista do CNPq.

(4) Professor Titular do Instituto de Ciências Agrárias, UFU. Bolsista do CNPq.

(5) Pós-graduando do do I nstituto de Ciências Agrárias, UFU.
} 


\begin{abstract}
de 0-45 cm de profundidade foi, em média, de 9,9 $\mathrm{kg} \mathrm{ha}^{-1}$ (10,0\% do $\mathrm{N}$ aplicado), da aplicação superficial ou incorporada, e do $\mathrm{N}$-uréia do uran foi de $3,3 \mathrm{~kg} \mathrm{ha}^{-1}$ ( $7,6 \%$ do $\mathrm{N}$ aplicado). $\mathrm{O} \mathrm{N}$-mi neral no solo derivado do $\mathrm{N}$ da uréia e do $\mathrm{N}$-uréia do uran aplicados na superfície, no perfil de 0-150 cm, foi, respectivamente, de 2,4 e $3,2 \%$, e de 5,9 e $2,5 \%$, com as fontes incorporadas. No balanço global de $\mathrm{N}$, em média, 13,7 e 50,3\% do $\mathrm{N}$ da uréia não foram recuperados no sistema solo-planta, respectivamente, para a aplicação superficial ou incorporada; para o $\mathbf{N}$-uréia do uran, obtiveram-se, respectivamente, 47,7 e $57,6 \%$.
\end{abstract}

Termos de Indexação: plantio direto, imobilização, N-recuperado planta, lixiviação, milho, uréia, uran, volatilização de $\mathbf{N}-\mathrm{NH}_{3}$.

\title{
SUMMARY: NITROGEN BALANCE OF SOLID AND LIQUID NITROGEN SOURCES ON SIDE-DRESSED NO-TILL CORN SYSTEM AT TRIÂNGULO MINEIRO (MG)
}

\begin{abstract}
U rea and uan weresidedressed applied on thesoil surface and incorporated $(5-7 \mathrm{~cm})$ to corn in a no-till age system to study the balance of urea- $\mathrm{N}\left({ }^{15} \mathrm{~N}\right)$ at harvest and measure the accumulated losses of $\mathrm{NH}_{3}-\mathrm{N}$ derived from these sources and from urea $+\mathrm{KCl}$ (solid) and uan $+\mathrm{KCl}$ (liquid), applied as 06-00-09 $\left(\mathrm{N}-\mathrm{P}_{2} \mathrm{O}_{5}-\mathrm{K}_{2} \mathrm{O}\right)$ to thesurfaceonly. Thetreatmentsoriginated from a factorial $1+(2 \times 2)+2$, with pl ot being + factorial $2 \times 2$ (two sources; urea and uan $\mathrm{x}$ two forms of application) + two additional treatments, urea $+\mathrm{KCl}$ mixture (solid) and uan $+\mathrm{KCl}$ (liquid) - were arranged in a randomized block design with four replications. The experiment was conducted on a high clay soil (Typic Acrustox) from the savanna region at Novartis Research Center - Seeds in U berlândia (MG). Nitrogen treatments (approximately $100 \mathrm{~kg} \mathrm{ha}^{-1}$ ) were sidedressed at 6-8 leaf phase of corn growth. The accumulated losses of $\mathrm{NH}_{3}-\mathrm{N} 26$ days after $\mathrm{N}$ had been applied, showed that surface applications were of $54,41,17$ and $14 \%$ for urea, urea $+\mathrm{KCl}$, uan and uan $+\mathrm{KCl}$, respectively. When urea and uan wereincorporated into thesoil, the $\mathrm{N}$ accumulated losses were 5.0 and $3.5 \%$ from the total $\mathrm{N}$ applied. At harvest, the amount of urea- $\mathrm{N}$ from urea accumulated in the plant (root + stalk + leaves + grain) was $19.9 \mathrm{~kg} \mathrm{ha}^{-1}$ (or $20.8 \%$ of applied $\mathrm{N}$ ) and $29.5 \mathrm{~kg} \mathrm{ha}^{-1}$ (or $29.5 \%$ of applied $\mathrm{N}$ ) when $\mathrm{N}$ was applied and incorporated to the surface, respectively. It was observed that $11.4 \mathrm{~kg} \mathrm{ha}^{-1}(26.1 \%)$ was accumulated by the plant from urea-N of uan when uan was applied to the surface and $11.7 \mathrm{~kg} \mathrm{ha}^{-1}(26.8 \%)$ when incorporated. The immobilized urea-N from surface and incorporated urea in the soil (0$45 \mathrm{~cm}$ ) was of $9.9 \mathrm{~kg} \mathrm{ha}^{-1}(10.0 \%$ of applied $\mathrm{N})$ and $3.3 \mathrm{~kg} \mathrm{ha}^{-1}(7.6 \%$ of applied $\mathrm{N})$ from urea-N of uan. Theamount of mineral $\mathrm{N}$ present in thesoil derived from urea-N of urea and uan in the profile $0-150 \mathrm{~cm}$, was 2.4 and $3.2 \%$, respectively, of the total $\mathrm{N}$ applied to the surfaceand 5.9 and $2.5 \%$, when incorporated. Thegl obal $\mathrm{N}$ bal anceindicated that 13.7 and $50.3 \%$ from urea- $\mathrm{N}$ werenot recovered when applied tothesurfaceand incorporated, respectively, and 47.7 and $57.6 \%$ of urea-N from uan, was not recovered in the soil-plant system.
\end{abstract}

Index Terms: no-tillage, immobilization, nitrogen plant recovery, lixiviation, corn, urea, uan, volatilization of $\mathrm{NH}_{3}-\mathrm{N}$.

\section{NTRODUÇÃO}

A baixa eficiência de uso do $\mathrm{N}$ de fertilizantes pelas culturas deve-se a quatro processos queatuam simultaneamente de forma direta: as perdas por volatilização de amônia e a desnitrificação, o escorrimento superficial, a lixiviaçãoe a imobilização microbiana. Por sua vez, a utilização do N-fertilizante pelas plantas pode ser maximizada, Iocalizando-se o adubo na região mais ativa do sistema radicular, aplicando-se o fertilizante no estádio fisiológico da cultura de maior demanda pelo nutriente, aliando condições adequadas de regime hídrico a práticas de manejo (Olson \& Kurtz, 1982).

A quantificação dessa eficiência só é possível com o uso de fertilizantes marcados com o isótopo ${ }^{15} \mathrm{~N}$, constituindo o único método direto para esse fim. O método da diferença (eficiência aparente), utilizado na maioria dos estudos efetuados no País, fornece uma medida do impacto da aplicação do fertilizante na absorção total de $\mathrm{N}$ pela planta $(\mathrm{N}$-nativo $+\mathrm{N}$ fertilizante) e assume que a mineralização, 
imobilização e outras transformações do N são as mesmas em áreas fertilizadas ou não, o que sabidamente não ocorre (Westerman \& Kurtz, 1974). A adição de $\mathrm{N}$ ao solo acelera a mineralização de $\mathrm{N}$ orgânico, aumentando a disponibilidade de N-nativo e, conseqüentemente, levando a uma superestimativa da quantidade de $\mathrm{N}$-fertilizanteabsorvido pela planta (Fried et al., 1975; Calvacheet al., 1982). Esta última afirmativa só é válida para sol os com adição de resíduos orgânicos, como éo caso do sistema plantio direto (J enkinson et al., 1985; Rao et al., 1992).

Westerman \& Kurtz (1974) concluíram que o método da diferença pode servir para fazer comparações quantitativas de diferentes fertilizantes ou modos de aplicação, não sendo possível efetuar medidas precisas da eficiência do fertilizante. Exemplos que mostram a superestimativa da eficiência quando utilizado o método da diferença, são apresentados em estudos coordenados pela $\mathrm{FAO/}$ I AEA (FAO/I AEA, 1970a,b).

Diversos estudos realizados com milho mostram grande variação na determinação da eficiência pelo método isotópico: de 40\% (L atkovicz et al ., 1968); de 30 a $68 \%$ (Broadbent \& Carlton, 1978) e de 26,2\% (Calvache et al., 1982). Estudos citados por Coel ho et al . (1991) mostraram que quantidades apreciáveis de $\mathrm{N}$-fertilizante permaneceram imobilizadas nas camadas superficiais dos solos $(0-30 \mathrm{~cm})$, e o N não contabilizado no balanço solo-planta possivel mente havia sido perdido por desnitrificação e, ou, volatilização amoniacal, uma vez que eram pequenas as quantidades de $15 \mathrm{~N}$-fertilizante lixiviadas e encontradas nas camadas mais profundas do solo (100-200 cm). O balanço-15N, realizado por Coel ho et al. (1991) em solo de cerrado (Sete Lagoas), da aplicação superficial e incorporada de $60 \mathrm{~kg} \mathrm{ha-1}$ de $\mathrm{N}$-uréia na cultura do milho, mostrou que, em média, $56 \%$ foram recuperados na planta, $23 \%$ ficaram retidos na camada de $0-90 \mathrm{~cm}$ do solo e $15 \%$ foram perdidos do sistema.

No sistema plantio direto, o conceito de eficiência da fertilização nitrogenada é mais abrangente que no sistema convencional, uma vez que as doses de $\mathrm{N}$ são definidas de acordo com o sistema e não com as culturas. Sá (1998) enfatizou esta idéia, assinalando que, no sistema plantio direto, a produção de material vegetal (palhas e grãos), a exigência nutricional e os sistemas radiculares diferenciados objetivam uma rotação de culturas integrada e sustentável. Portanto, o uso do isótopo ${ }^{15} \mathrm{~N}$ para as medidas da eficiência de fertilizações nitrogenadas ea utilização de estudos de bal anço nitrogenado que forneçam antecedentes das entradas e que avaliem as perdas e os processos de transformação do $\mathrm{N}$ no sistema são essenciais (Legg \& M eisinger, 1982). Assim, será possível compreender mel hor os fatores que afetam a dinâmica do N no sistema em estudo, favorecendo a maximização na eficiência de utilização do $\mathrm{N}$ e a conseqüente minimização do impacto ambiental associado às possíveis perdas.
O objetivo deste trabal ho foi estudar o balanço$15 \mathrm{~N}$ do $\mathrm{N}$ da uréia e do $\mathrm{N}$-uréia do uran, com as fontes aplicadas em superfície ou incorporadas $(5-7 \mathrm{~cm})$, na cobertura nitrogenada de milho em sistema plantio direto, bem como quantificar as perdas por volatilização de $\mathrm{N}-\mathrm{NH}_{3}$ nesses tratamentos e na aplicação superficial das misturas de uréia $+\mathrm{KCl}$ (sólida) e uran $+\mathrm{KCl}$ (fluida).

\section{MATERIAL E MÉTODOS}

O experimento foi instalado no Centro de Pesquisa Novartis - Seeds, município de U berlândia (MG), no ano agrícola 1995/96, em Latossolo Vermelho-E scuro distrófico muito argiloso fase cerrado. A análise granulométrica e a análise química da camada de solo $0-10 \mathrm{~cm}$ de profundidade revel aram as seguintes características: $\mathrm{pH}\left(\mathrm{H}_{2} \mathrm{O}\right) 6,4$; $54 \mathrm{mg} \mathrm{dm}^{-3}$ de $\mathrm{P}$ (Mehlich-1); 3,3 $\mathrm{mmo}_{\mathrm{C}} \mathrm{dm}^{-3}$ de $\mathrm{K}+$; CTC de $70 \mathrm{mmol}_{\mathrm{c}} \mathrm{dm}^{-3} ; 72 \%$ de saturação por bases e $32 \mathrm{~g} \mathrm{dm}^{-3}$ de MO. O solo da camada de $10-20 \mathrm{~cm}$ apresentou $\mathrm{pH}\left(\mathrm{H}_{2} \mathrm{O}\right) 6,4 ; 13,8 \mathrm{mg} \mathrm{dm}^{-3}$ deP (Mehlich1); $2,5 \mathrm{mmol}_{\mathrm{C}} \mathrm{dm}^{-3}$ deK +, CTC de $60 \mathrm{mmol}_{\mathrm{C}} \mathrm{dm}^{-3} ; 70 \%$ de saturação por bases e $30 \mathrm{~g} \mathrm{dm}^{-3}$ de MO.

O híbrido de milho, triplo, Exceler, semiprecoce, foi semeado em 6/12/95 em sistema plantio direto, com espaçamento de $0,8 \mathrm{~m}$, com densidade de seis sementes por metro de sulco (75.000 plantas ha-1), sobre resteva de 1,91 $\pm 0,58 \mathrm{t}^{\text {h-1 }} 1$ de palhada de milheto (Pennisetum typhoides) cv. I taliano. No sulco de semeadura, comum aos tratamentos, realizou-se a aplicação de 44; 35 e $52 \mathrm{~kg}$ ha-1 de N; $\mathrm{P}_{2} \mathrm{O}_{5}$ e K ${ }_{2} \mathrm{O}$ nas formas de uréia (não marcada com $15 \mathrm{~N}$ ), superfosfato triplo e $\mathrm{KCl}$, respectivamente, e de 3,6; 0,$7 ; 0,3 ; 1,2 ; 0,8$ e $0,04 \mathrm{~kg} \mathrm{ha}^{-1}$ de Zn, B, Cu, Fe, Mn e Mo, respectivamente. Foram efetuados os tratos culturais de controle de pragas e plantas daninhas adequados para a região. Após 20 dias da semeadura, efetuou-se desbaste manual para deixar uma população efetiva de 45.000 plantas ha-1.

Utilizaram-sesetetratamentos que se originaram de um fatorial $1+(2 \times 2)+2$, sendo a testemunha + o fatorial $2 \times 2$ (duas fontes; uréia e uran $\times$ duas formas de local ização) +dois tratamentos adicionais, misturas uréia $+\mathrm{KCl}$ (sólida) e uran $+\mathrm{KCl}$ (fluida). Cada parcela foi constituída de quatro linhas com 30 m de comprimento. Os tratamentos foram dispostos em blocos casualizados com quatro repetições. Os tratamentos de cobertura nitrogenada realizada no estádi o fenológico de quatro a seis fol has consistiram na dose zero (testemunha) e na aplicação de cerca de $100 \mathrm{~kg} \mathrm{ha}^{-1}$ de nitrogênio no meio das entrel inhas, atendendo às seguintes fontes e aos modos de aplicação: uréia euran (solução de nitrato de amônio +uréia, 32\% de N) doses aplicadas superficial mente e incorporadas a 5 e $7 \mathrm{~cm}$, uréia $+\mathrm{KCl}$ (sólida) e uran $+\mathrm{KCl}$ (fluida) como formulados 6-0-9, aplicadas somenteem superfície. Em duas das quatro repetições 
dos tratamentos que receberam uréia e uran aplicados na superfície e incorporados, foi efetuado o balanço-15N na colheita, utilizando-se uréia $(46,76 \% \mathrm{~N})$, marcada com $5,3 \pm 0,1 \%$ de abundância em átomos de $15 \mathrm{~N}$, e uran $(32,0 \% \mathrm{~N})$, marcado no componente uréia, com igual abundância isotópica. As fontes marcadas foram aplicadas em microparcelas não confinadas de 1,5 x 1,6 m, constituídas pel o sulco de adubação e de duas linhas adjacentes de plantas. No quadro 1, encontram-se as doses de $\mathrm{N}$ das fontes marcadas, expressas em $\mathrm{mg} \mathrm{m}^{-2}$ e em $\mathrm{kg} \mathrm{ha}^{-1}$; doses queforam efetivamente aplicadas nas microparcelas.

O uran marcado com ${ }^{15} \mathrm{~N}$ no componente uréia foi preparado em laboratório, misturando em solução aquosa a uréia-15N e o nitrato de amônio comercial . A adubação de cobertura nas parcelas foi mecanizada. Nas microparcelas, a aplicação das fontes marcadas foi realizada manual mente.

Após 65 dias da semeadura, procedeu-se à amostragem da folha +4 em 10 plantas, nas duas linhas centrais de cada parcela, para avaliação do teor foliar de nitrogênio e de potássio (Trani et al., 1983).

A col heita foi realizada em $28 / 03 / 96$. Nas duas linhas centrais de cada parcela, foram determinadas a população efetiva de plantas ea produção de grãos (umidade corrigida para $130 \mathrm{~g} \mathrm{~kg}^{-1}$ ).

Nas microparcelas que receberam o adubo marcado com $15 \mathrm{~N}$, foi efetuado o bal anço de nitrogênio de acordo com a seguinte expressão:

$$
\mathrm{Naf}=\mathrm{Nppf}+\mathrm{N} \text { cobf }+\mathrm{Nspf}_{(0-150)}+\mathrm{Nvolpf}
$$

sendo $\mathrm{N}$ af $=\mathrm{N}$-uréia aplicado como fertilizante marcado; $\mathrm{Nppf}=\mathrm{N}$-total na planta derivado do fertilizante; $\mathrm{Ncobf}=\mathrm{N}$-total na cobertura vegetal proveniente do fertilizante; $\mathrm{Nspf}_{(0-150)}=\mathrm{N}$ no solo atéà profundidade de $150 \mathrm{~cm}$, derivado dofertilizante, e N vol pf $=\mathrm{N}$ volatilizado como amônia, derivado do fertilizante.
O Nppf foi determinado em plantas (10 a 12 plantas) col hidas em 1,25 metrolinear central nas duas linhas das microparcelas. O material foi fracionado em parte aérea, incluindo a palha, colmo e o sabugo das espigas após trituração e homogeneização do material, grãos e raízes. O nitrogênio da parte aérea e dos grãos foi determi nado por digestão sulfúrica e destilação Kjeldahl pelo método de Parkinson \& Allen (1975). O material foi preparado pelo método da via úmida de Rittemberg para posterior determinação da abundância de $15 \mathrm{~N}$ por espectrometria de massas no Centro Energia Nuclear na Agricultura, USP-Piracicaba, de acordo o método descrito por Trivelin et al. (1973). Efetuaram-se os cálculos da concentração (\%) e da quantidade de nitrogênio ( $\mathrm{kg} \mathrm{ha}-1)$ no grão, parte aérea e raízes derivada do fertilizante ( $\mathrm{Nppf}$ ) de acordo com as seguintes expressões:

$$
\mathrm{Nppf}(\%)=(\mathrm{A}-\mathrm{C}) /(\mathrm{B}-\mathrm{C}) \times 100
$$

Nppf $\left(k_{\text {h ha-1) }}\right)=(\mathrm{N} \mathrm{ppf}(\%) / 100) \times$ NT (kg ha-1) (3) significando $\mathrm{A}=$ concentrações de $15 \mathrm{~N}$ (\% de abundância em átomos de $15 \mathrm{~N}$ ) do grão, parte aérea eraízes, $\mathrm{B}=$ concentração de $15 \mathrm{~N}$ do fertilizante e $\mathrm{C}$ =concentração isotópica natural do solo $(0,370 \%$ de abundância em átomos de $15 \mathrm{~N}$ ), respectivamente, e NT = quantidade de $\mathrm{N}$-total nas diferentes partes da planta ( $\left.\mathrm{kg} \mathrm{ha}^{-1}\right)$.

A recuperação do $\mathrm{N}$-fertilizante $(\mathrm{R})$ foi determinada pela expressão:

$$
\mathrm{R}(\%)=[\mathrm{Nppf}(\mathrm{kg} \mathrm{ha}-1)] / \mathrm{Naf}
$$

significando $\mathrm{N}$ af o $\mathrm{N}$-fertilizante aplicado.

As raízes presentes nas camadas de 0-15; 15-30; 30-45 e 45-60 cm da área útil das microparcelas $(1,25 \times 1,20 \mathrm{~m})$ foram separadas da terra, utilizando-se peneira de $4 \mathrm{~mm}$, sendo, posteriormente, lavadas com água destilada, secas em estufa a $60^{\circ} \mathrm{C}$, passadas

\begin{tabular}{|c|c|c|c|c|c|}
\hline \multicolumn{2}{|c|}{ Tratamento } & \multicolumn{2}{|c|}{ N aplicado sob coletores(1) } & \multicolumn{2}{|c|}{ N uréia na microparcela(2) } \\
\hline Fonte & Modo de aplicação & E fetivo & Por ha & E fetivo & Por ha \\
\hline & & $\mathrm{mg} \mathrm{m}^{-2}$ & $\mathrm{~kg} \mathrm{ha}^{-1}$ & $\mathrm{mg} \mathrm{m}^{-2}$ & kg ha-1 \\
\hline Testemunha & - & - & - & - & - \\
\hline Uréia & $\begin{array}{l}\text { Superficial } \\
\text { Incorporada }\end{array}$ & $\begin{array}{l}9.111 \\
9.116\end{array}$ & $\begin{array}{l}91,1 \\
91,2\end{array}$ & $\begin{array}{r}9.567 \\
10.000\end{array}$ & $\begin{array}{r}95,7 \\
100,0\end{array}$ \\
\hline Uran & $\begin{array}{l}\text { Superficial } \\
\text { Incorporada }\end{array}$ & $\begin{array}{l}11.119 \\
10.911\end{array}$ & $\begin{array}{l}111,2 \\
109,1\end{array}$ & $\begin{array}{l}4.360 \\
4.360\end{array}$ & $\begin{array}{l}43,6 \\
43,6\end{array}$ \\
\hline Uréia + KCl & Superficial & 9.911 & 99,1 & - & - \\
\hline Uran $+\mathrm{KCl}$ & Superficial & 9.626 & 96,3 & - & - \\
\hline
\end{tabular}

Quadro 1. Doses de $\mathbf{N}$ aplicadas sob os coletores de amônia que receberam uréia e uran não marcadas e nas microparcelas que receberam ${ }^{15} \mathrm{~N}$-uréia das mesmas fontes

(1) Média de seis repetições, para as fontes aplicadas na superfície, e de cinco repetições, para as fontes incorporadas. ${ }^{(2)}$ Média de duas repetições. 
em moinho Wiley, e determinados o $\mathrm{N}$-total e a concentração de $15 \mathrm{~N}$, como indicado anteriormente.

O N cobf foi determinado a partir da col heita de todo o material vegetal de cobertura do solo presente na superfície útil das microparcelas (material vivo e morto), para posterior determinação de $\mathrm{N}$-total e concentração de $15 \mathrm{~N}$, como indicado nas expressões 2 e 3.

O Nspf $(0-150)$ foi definido pelo $\mathrm{N}$ no solo derivado da uréia e uran, de acordo as seguintes expressões:

$$
\begin{aligned}
\mathrm{Nspf}_{(0-150)} & =\mathrm{Nipf}_{(0-45)}+\mathrm{Nmpf}_{(0-150)} \\
\mathrm{Nipf}_{(0-45)} & =\mathrm{Ntpf}_{(0-45)}-\mathrm{Nmpf}_{(0-45)}
\end{aligned}
$$

significando: $\mathrm{Nipf}_{(0-45)}=\mathrm{N}$-orgânico proveniente do fertilizante até à profundidade de $45 \mathrm{~cm}$ e o $\mathrm{Nmpf}_{(0-150)}$ $=\mathrm{N}$-mineral derivado do fertilizante determinado até à profundidade de $150 \mathrm{~cm}$. $\mathrm{O} \mathrm{Nipf}(0-45)$ foi determinado pela diferença entre o $\mathrm{N}$-total $\left[\mathrm{Ntpf}_{(0-45)}\right]$ e o $\mathrm{N}$-mineral $\left[\mathrm{Nmpf}_{(0-45)}\right]$ na camada de $0-45 \mathrm{~cm}$ de profundidade, correspondendo ao $\mathrm{N}$-imobilizado do fertilizante. O Ntpf $(0-45)$ foi calculado por expressões similares a (2) e (3) a partir da determinação do Ntotal (incluindonitratos, McGill \& Figueiredo, 1993) e a concentração de $15 \mathrm{~N}$ por espectrometria de massas. O $\mathrm{Nmpf}_{(0-150)}$ foi calculado a partir da destilação do $\mathrm{N}$-mineral total com MgO e Liga de Devarda (Kenney \& Nelson, 1982) e posterior determinação da concentração de $15 \mathrm{~N}$. Todo o solo retirado das camadas de 0-15; 15-30; 30-45 e 45-60 cm foi subamostrado por quartejamento, edas camadas 60-90; 90-120 e120-150 cm, foi efetuada a amostragem composta a partir de cinco subamostras retiradas com trado. Atéà camada de $60 \mathrm{~cm}$, foi determinada a densidade do solo (método do anel volumétrico), previamente à coleta do solo, para expressar os conteúdos de $\mathrm{N}$-orgânico e $\mathrm{N}$-mineral do solo provenientes do $\mathrm{N}$-uréia dos fertilizantes em kg ha-1. Para as camadas inferiores a $60 \mathrm{~cm}$, foi considerado o val or médio da densidade de $1,26 \mathrm{~g} \mathrm{~cm}-3$, igual ao determinado para a camada de 45-60 cm, assumindose a homogeneidade do perfil até $150 \mathrm{~cm}$. Todos os cál cul os de $\mathrm{N}$ foram referidos com base na massa de solo seco em estufa a 105ㄷ C até peso constante.

$\mathrm{O} \mathrm{N}$ volatilizado das fontes ( $\mathrm{N}$ volpf) foi determinado em coletor de amônia semi-aberto estáti co adaptado de Nömmik (1973) e cal ibrado por Lara Cabezas et al. (1999), para estimar as perdas reais em condições de campo, como mostrado em trabalhos anteriores (Lara Cabezas et al., 1997a,b). Nos tratamentos com aplicação superficial de uréia, uran, uréia $+\mathrm{KCl}$ (sólida) e uran $+\mathrm{KCl}$ (fluida), foram instalados, em três das quatro repetições, seis coletores de amônia e cinco unidades somente, em três das quatro repetições dos tratamentos com aplicação incorporada de uréia e uran. As doses médias de $\mathrm{N}$ efetivamente aplicadas ao solo no interior dos col etores de amônia foram tomadas com base na calibração da adubadeira e do diâmetro do col etor eexpressas em $\mathrm{mg} \mathrm{m}^{-2}$ eem $\mathrm{kg} \mathrm{ha}^{-1}$ (Quadro 1 ). Os col etores foram instalados fora das microparcelas com ${ }^{15} \mathrm{~N}$-uréia, para evitar alteração do comportamento da fonte na presença do col etor. No tratamentotestemunha, não foram instal ados col etores, dado seu número limitado, uma vez que as perdas de amônia do solo são desprezíveis em relação às perdas derivadas das fontes para o intervalo de tempo considerado (Lara Cabezas et al., 1999). Seis amostragens para a determinação do $\mathrm{N}-\mathrm{NH}_{3}$ volatilizado foram efetuadas, coletando-se o absorvedor inferior do coletor de amônia, em intervalos de quatro a cinco dias. Os discos absorvedores foram guardados em saco plástico earmazenados em geladeira $\left(5^{\circ} \mathrm{C}\right)$ para posterior extração da amônia retida. O N-N $\mathrm{N}_{3}$ retido no disco foi extraído, determinado e calculada a concentração (\%) do N retido em relação ao aplicado, de acordo com Lara Cabezas et al. (1999).

A pluviosidade e as temperaturas médias, máximas e mínimas, foram avaliadas durante o período experimental (Figura 1).

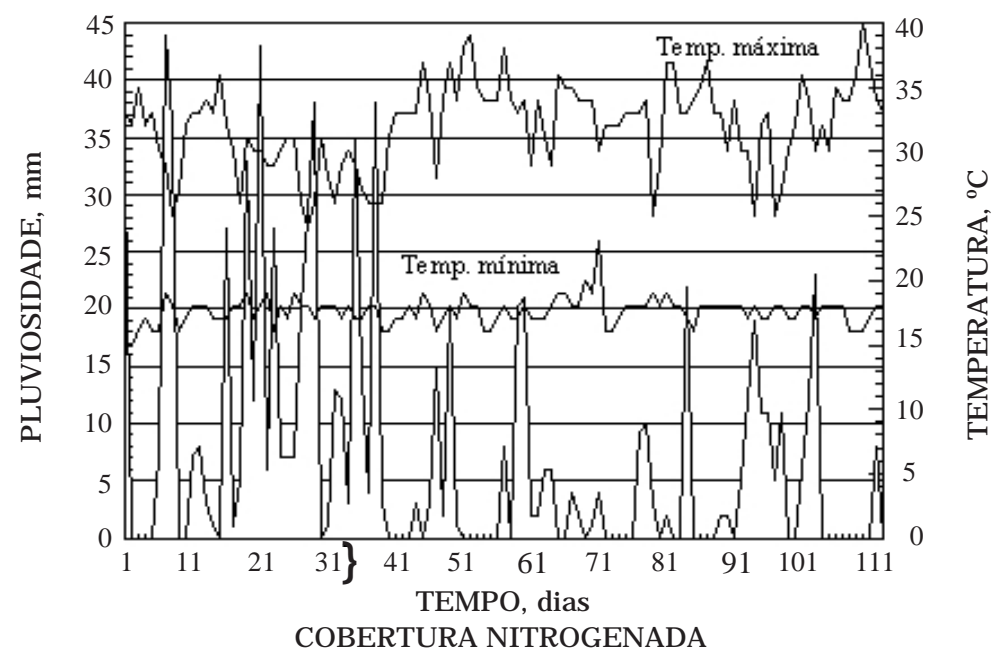

Figura 1. Distribuição da pluviometria etemperaturas máximas e mínimas durante o período experimental. 
O efeito das fontes e modos de aplicação (uréia e uran aplicados na superfície e incorporados) nos componentes do balanço nitrogenado e as médias das perdas de $\mathrm{N}-\mathrm{NH}_{3}$ volatilizado das fontes foram avaliados por análise de variância, e as médias dos tratamentos comparadas pel o teste de Tukey a $5 \%$. Também se correlacionaram a produção de matéria seca ea absorção de $\mathrm{N}$ total pela planta. Por ajuste de regressão linear, foi estimada a produtividade em função das perdas acumuladas de $\mathrm{N}$-amoniacal volatilizado.

\section{RESULTADOSE DISCUSSÃO}

\section{Perdas de $\mathrm{N}$-amoniacal dos fertilizantes e seu efeito na produtividade do milho}

As perdas acumuladas de $\mathrm{N}$-amoniacal após, aproxi madamente, 26 dias da cobertura constam da figura 2. Houve perdas significativas de $\mathrm{N}-\mathrm{NH}_{3}$, quando as fontes foram aplicadas na superfície do solo. A volatilização nos tratamentos com as fontes incorporadas ao solo foram insignificantes e excluídas da comparação.

Em ordem decrescente, para as fontes aplicadas em superfície, as perdas por volatilização de $\mathrm{N}-\mathrm{NH}_{3}$ foram de 54, 41, 17 e 14\% do N aplicado, para a uréia, uréia $+\mathrm{KCl}$, uran e uran $+\mathrm{KCl}$, respectivamente. Com base nesses resultados, cabe salientar que as maiores perdas mostraram relação com a maior concentração do N-amídico no fertilizante (uréia 45\% euran $14 \%$ ). Em relação ao $\mathrm{KCl}$ adicionado junto às fontes uréia euran, Fenn (1987) indicou que a adição de potássio à uréia pode tomar o lugar do cálcio ou do magnésio no solo e prevenir as perdas por volatilização de amônia. O potássio desl oca o cál cio adsorvido no colói de do sol o e na solução do sol o irá reagir com o carbonato de amônio (produto da hidrólise da uréia), formando carbonato de cál cio. A incorporação das fontes (5-7 cm de profundidade), mostrou ser a forma mais eficiente de controlar as perdas (5,0 e 3,5\% do N aplicado, para as fontes uréia e uran, respectivamente). Diversos autores têm demonstrado claramentequea incorporação da uréia diminui efetivamente as perdas de amônia (Ernst \& Massey, 1960; Overrein \& Moe, 1967; Fenn \& Kissel, 1976; Anjos \& Tedesco, 1976). O sol o úmido, associadoa al tas temperaturas, de ocorrência comum na época da aplicação da cobertura nitrogenada no cerrado, favorece, notadamente, as perdas por volatilização, quandoa uréia éaplicada na superfície do solo (Prasad, 1976; Vlek \& Stumpe, 1978; Lara Cabezas et al., 1997a,b).

As perdas de $\mathrm{N}$-amoniacal provenientes da uréia e do uran aplicados em superfície e incorporados, foram utilizadas na elaboração do balanço nitrogenado. A adição de aditivos à uréia e ao uran de caráter inibitório da atividade da urease do solo, testada em diferentes culturas, principalmente em sistema plantio direto, pode ser uma alternativa eficaz quando a adubação é realizada na superfície do solo (Agrotain, 1997). A figura 3 mostra a correlação entre as produtividades de milho e as respectivas perdas acumuladas de $\mathrm{N}$ amoniacal das fontes nitrogenadas. Considerando os valores estimados pelo ajuste, pode-se estimar uma redução de $9,9 \mathrm{~kg} \mathrm{ha}-1$ de grãos para cada $1 \%$ de $\mathrm{N}$ volatilizado. Portanto, para uma perda por volatilização de $50 \%$ do $\mathrm{N}$ aplicado na superfície, a redução na produtividade seria, em média, de 495,0 kg ha-1 de grãos (8,3 sacas de milho). Em trabalhos anteriores, real izados em diferentes épocas e condições experimentais, foram obtidos resultados similares (Lara Cabezas et al., 1997a,b).

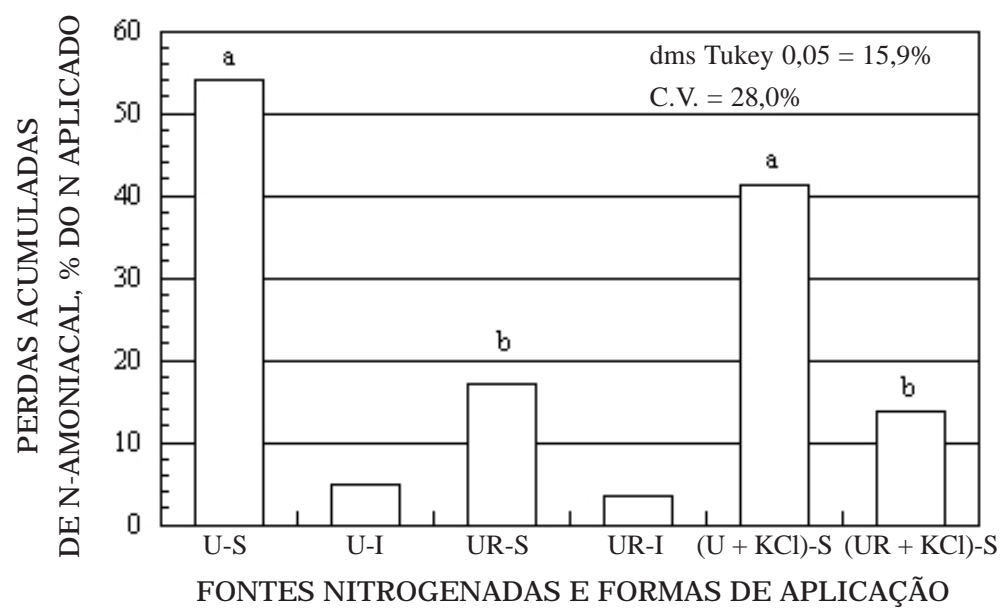

Figura 2. Perdas acumuladas de $\mathrm{N}$-amoniacal provenientes da aplicação superficial (S) e incorporada (I) das fontes uréia (U); uran (UR); uréia $+\mathrm{KCl}$ (sólida) e uran $+\mathrm{KCl}$ (fluida) na cobertura nitrogenada de mil ho em sistema plantio direto. Médias com letras minúsculas desiguais diferem significativamente pelo teste de Tukey 5,0\%. Colunas sem letras não foram incluídas na análise estatística. 
Produção de matéria seca, nitrogênio na planta (Nppf) e na cobertura do solo (Ncobpf) proveniente dos fertilizantes

A produção de matéria seca nas diferentes partes da planta de milho (parte aérea, grãos e raízes) ea quantidade correspondente de nitrogêni o acumulado proveniente dos fertilizantes uréia e uran aplicados na superfície ou incorporados, encontram-se no quadro 2. Em média, independentemente dos tratamentos, a distribuição rel ativa da matéria seca foi de cerca de 41,48 , e 10\% no grão, parte aérea e raiz, respectivamente. A produção média diária de matéria seca foi de 118, 127 e de 136 e 96 kg ha-1, para a aplicação de uréia superficial e incorporada e do uran aplicado em superfície e incorporado, respectivamente.

Hanway (1962a,b), citado por Bull (1993), indicou que o acúmulo de matéria seca sofre influência do nível de fertilidade do solo. Sob condições de concentrações adequadas de N, P eK no sol o, o autor assinalou uma produção média diária de 245 kg ha-1, superior à registrada neste estudo. É provável que mai or população de plantas (60.000 plantas por ha-1) tivesse resultado em maior produção de matéria seca neste estudo.

Observando os tratamentos (Quadro 2), não houve diferença significativa na absorção total de nitrogênio pela planta, sendo de 152,0 kg ha-1 em média. O N exportado para o grão não apresentou maior variação entre os tratamentos, sendo, em média, de $51,8 \%$ do N-total absorvido. E ntre os modos de aplicação da uréia, o Nppf foi superior, quando efetuada a incorporação $(29,5 \mathrm{~kg}$ ha-1) em relação à aplicação em superfície (19,9 kg ha-1), tendo sido o $\mathrm{N}$ ppf da parte aérea superior com a incorporação da fonte $(12,0 \mathrm{~kg} \mathrm{ha}-1)$. Entretanto, comparando a eficiência do $\mathrm{N}$-uréia recuperado na planta, não foi observada diferença entre a aplicação superficial $(20,8 \%)$ e a incorporada (29,5\%). Alta densidade de raízes foi encontrada na camada superficial de 0 $15 \mathrm{~cm}\left(676,4 \mathrm{mg} \mathrm{kg}^{-1}\right.$ de solo) e valores abaixo de $8 \mathrm{mg} \mathrm{kg}^{-1}$ de raízes até à profundidade de $60 \mathrm{~cm}$. A penetração radicular deve ter sido afetada pela maior densidade do solo na camada de $15-30 \mathrm{~cm}$ : $1,34 \mathrm{~g} \mathrm{~cm}^{-3}$, com valores de 1,28 e $1,26 \mathrm{~g} \mathrm{~cm}^{-3}$ nas camadas de 30-45 e 45-60 cm de profundidade, respectivamente, o que deve ter contribuído para a baixa eficiência do $\mathrm{N}$-fertilizante. Valores similares de recuperação do $\mathrm{N}$-fertilizante pela planta têm sido relatados por diversos autores: 24 a $26 \%$ (Olson, 1980); 23 a 45\% (Kitur et al., 1984) e 15 a 33\% (Sanchez \& Blackmer, 1988). Valores de eficiência maiores estão associados a doses mais baixas de aplicação do Nfertilizante (Coel hoet al., 1991; Reddy \& Reddy, 1993). Para a uréia, cabe salientar que a grande diferença

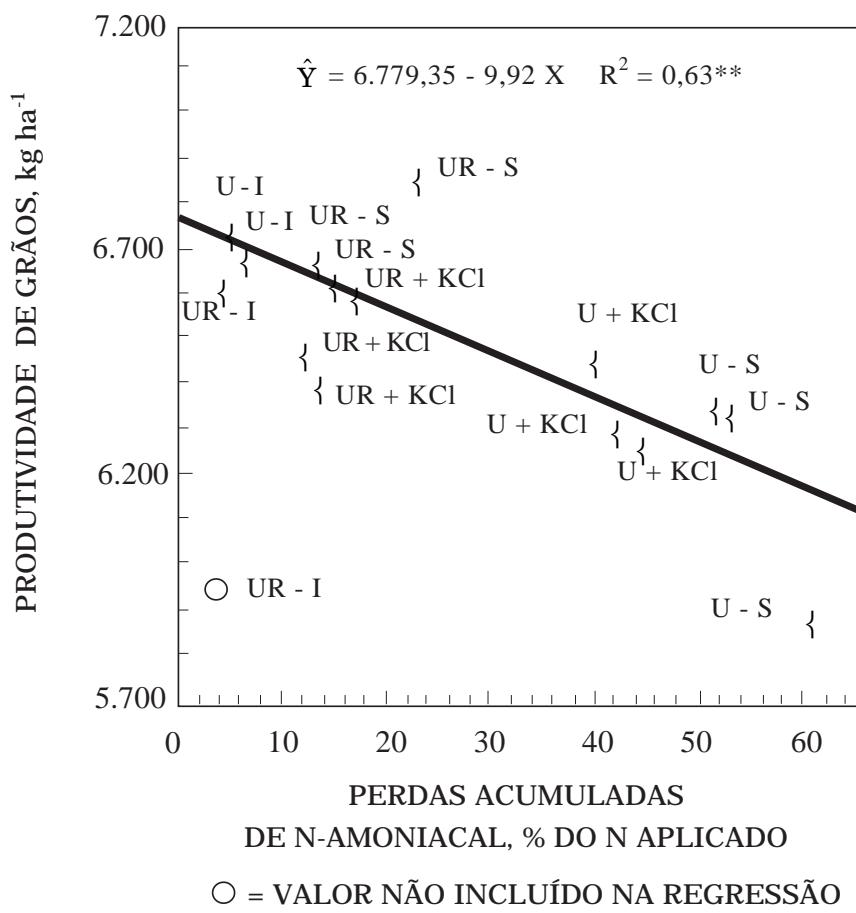

Figura 3. Efeito do $\mathrm{N}$-volatilizado das fontes uréia e uran aplicadas à superfície e incorporadas na produtividade do milho sob sistema plantio direto. U-S = uréia superficial; U-I = uréia incorporada; UR-S = uran superficial; UR-I = uran incorporado; U-KCI = uréia superficial + KCI e UR-KCI = uran superficial $+\mathrm{KCl}$. 
registrada entre as perdas por volatilização de amônia, quandoaplicada em superfíciee incorporada (54,2 e $5 \%$ do N, respectivamente), não refletiu em maior N ppf. Somente 9,6 kg ha-1 do $\mathrm{N}$-uréia a mais foram absorvidos, quando esta foi incorporada. Isto refletiu em produtividades similares: $6.314 \mathrm{e}$ $6.645 \mathrm{~kg} \mathrm{ha}-1$, quando a uréia foi aplicada na superfície ou incorporada, respectivamente.

Em estudos sem utilização do traçador $15 \mathrm{~N}$, nãoé possível efetuar o cál culo absoluto de absorção do $\mathrm{N}$-fertilizante, o quetem levado a conclusões erradas em trabal hos na literatura sobre o comportamento da uréia em relação a outras fontes nitrogenadas. $\mathrm{Em}$ condições de campo, alguns autores (Mello et al., 1988; Coel ho et al., 1991) assinalaram não ser a ocorrência do processo de volatilização de amônia da uréia significativa, quando não são observadas diferenças significativas de produtividade entre os modos de utilização da uréia e quando esta se compara com outras fontes nitrogenadas.

Cantarella \& Raij (1985), revisando diferentes trabal hos, mostraram que o comportamento da uréia em condições de campo foi similar ao de outros fertilizantes nitrogenados não sujeitos a perdas por volatilização de amônia em várias culturas. As limitações metodológicas na quantificação da vol atilização de amônia nessas condições explicam os resultados pouco expressivos (Cantarella \& Raij, 1985). A baixa eficiência da fonte, como a registrada neste trabalho, e, conseqüentemente, a expressiva absorção do N-nativo do sol o pela planta estariam mascarando diferenças significativas de produtividade.

Neste estudo, somente 14,6 e $18,6 \%$ do $\mathrm{N}$ total assimilado pela planta corresponderam à absorção do $\mathrm{N}$-uréia quando aplicado na superfície e incorporado, respectivamente. Essas diferenças dificilmente podem ser validadas pela estatística. Cabe assinalar que somente na ocorrência de importantes perdas por volatilização é possível encontrar-se correlação inversa entre produtividade e quantidade de perdas, como as determinadas neste estudo eem dois estudos precedentes (Lara Cabezas et al., 1997a,b). Quantidades de 116,6 e 129,2 kg ha-1 do $\mathrm{N}$-nativo do solo foram absorvidas pela planta, quando a uréia foi aplicada na superfície ou incorporada, respectivamente. Isto estaria refletindo o fenômeno de efeito "priming" observado em diversos trabal hos realizados com fontes marcadas. Esse efeito seria devido a um acréscimo da mineralização da matéria orgânica do sol o ou devido a uma substitui ção do "pool" no solo entre 15N e 14N (Calvache et al., 1982; Reddy \& Reddy, 1993). Recentemente, Lovell \& Hatch (1998) verificaram acentuada amonificação associada a um aumento da atividade respiratória da matéria microbiana, após a aplicação de $200 \mathrm{~kg} \mathrm{ha}^{-1}$ ano-1 de $\mathrm{N}$ em pastagem de Lolium perenne L. Outros processos, como por exemplo a imobilização, poderiam estar afetando a disponibilidade do $\mathrm{N}$-fertilizante aplicado, no caso da incorporação da uréia, o que não se refletiu em maior assimilação pela planta.

Para o uran, a recuperação do $\mathrm{N}$ na planta foi semel hante entre as formas deaplicação, com média de $26,5 \%$ do N-uréia douran (Quadro 2). Considerando que não foi incluído o nitrato de amôni o neste cál culo (não foi usada a fonte marcada com ${ }^{15} \mathrm{~N}$ ), admite-se que esta fonte deva ter sido mais eficiente que a uréia. Neste caso, as perdas de $\mathrm{N}$-volatilizado não foram expressivas (Figura 2) e entre os modos de aplicação não houve diferença significativa na recuperação do N-uréia pela planta. Tsai et al. (1991) assinalaram que o crescimento do milhoé estimulado quando é fornecida uma mistura de fontes que contenham amônio enitrato, o que não ocorre com a aplicação isolada dos produtos.

$\mathrm{Na}$ figura 4, fica evidente que houve um efeito positivo na produção de matéria seca do milho com a maior absorção de N. Bull (1993), citando diversos autores, assinal ou que as fol has bem nutridas em $\mathrm{N}$ assimilam mais $\mathrm{CO}_{2}$, aumentando a capacidade de síntese pela planta, o que resulta em maior acúmulo de matéria vegetal. Além disso, o $\mathrm{N}$ tem efeitos positivos sobre o maior crescimento do sistema radicular (Bull, 1993; Yamada, 1996) e sobre o aumento no comprimento e número de espigas por planta (Balko \& Russell, 1980; E bel har et al., 1987 citados por Bull, 1993).

No material de cobertura do solo (inço e palha), nos tratamentos assinalados no quadro 2 , a matéria seca variou de 752 a $1.246 \mathrm{~kg}$ ha-1, com conteúdo de $\mathrm{N}$-total de 9,8 até $17,9 \mathrm{~kg} \mathrm{ha}^{-1}$, sendo de 0,1 até $0,6 \mathrm{~kg}$ ha-1 o $\mathrm{N}$ proveniente do fertilizante. Como esperado, os mai ores val ores foram encontrados nos tratamentos em quea uréia eo uran foram aplicados em superfície. Estes valores não foram incluídos no quadro 2.

\section{Nitrogênio total (Ntpf), N-mineral total (Nmpf) e $\mathbf{N}$-imobilizado no solo proveniente do fertilizante (Ni pf) na profundidade de $0-45 \mathrm{~cm}$}

Verifica-se, no quadro 3, que o Ntpf entre as formas de aplicação da uréia, atéà profundidade de $45 \mathrm{~cm}$, não mostrou diferença (10,9 e11,3 kg ha-1 de N em superfície e incorporada, respectivamente), o mesmo ocorrendo com o uran (3,3 e 5,1 kg ha-1 do Nuréia). A aplicação superficial das duas fontes concentrou na camada de 0-15 cm, 95,4 e 70,0\% do $\mathrm{N}$-uréia dos fertilizantes uréia e uran, respectivamente, e, quando tais fontes foram incorporadas nessa camada, a concentração mostrou-se inferior (74,3 e 38,8\%). Coel ho et al. (1991) também observaram grande concentração do $\mathrm{N}$-uréia (médias da aplicação superficial e incorporada) na camada de 0-15 cm. O uran, por outrolado, como fontefluida, mostrou maior distribuição do $\mathrm{N}$ até $45 \mathrm{~cm}$ de profundidade (Quadro 3). O N mpf foi, em geral, reduzido, sendo de 0,80 e 1,70 kg ha-1 do N-uréia, quando aplicado em superfície e incorporado, 
Quadro 2. Produção de matéria seca e nitrogênio recuperado na planta (Nppf-grão, parte aérea e raiz) proveniente dos fertilizantes uréia e uran aplicados na superfície ou incorporados na cobertura nitrogenada do milho em sistema plantio direto(1)

\begin{tabular}{|c|c|c|c|c|c|c|c|}
\hline \multirow{2}{*}{ Fonte } & \multirow{2}{*}{$\begin{array}{c}\text { Forma } \\
\text { de aplicação }\end{array}$} & \multirow{2}{*}{$\begin{array}{l}\text { Matéria } \\
\text { seca }\end{array}$} & \multirow{2}{*}{ N-total } & \multirow{2}{*}{$\begin{array}{c}\text { Concentração } \\
\text { de }{ }^{15} \mathrm{~N}\end{array}$} & \multicolumn{2}{|l|}{ Nppf } & \multirow{2}{*}{$\begin{array}{l}\text { N-uréia } \\
\text { recuperada }\end{array}$} \\
\hline & & & & & Concentração & Por ha & \\
\hline & & $-\mathrm{kg} \mathrm{I}$ & $a^{-1}$ & Átom \% abun & $\%$ & $\mathrm{~kg} \mathrm{ha}^{-1}$ & $\%$ \\
\hline \multicolumn{8}{|c|}{ Parte aérea } \\
\hline \multirow[t]{2}{*}{ U réia } & $\begin{array}{l}\text { Superficial } \\
\text { Incorporada }\end{array}$ & $\begin{array}{l}6.268 \\
7.143\end{array}$ & $\begin{array}{l}55,2 \\
68,7\end{array}$ & $\begin{array}{l}1,016 \\
1,231\end{array}$ & $\begin{array}{l}13,1 \\
17,5\end{array}$ & $\begin{array}{r}7,2 \mathrm{~b} \\
12,0 \mathrm{a}\end{array}$ & $\begin{array}{r}7,5 \\
12,0\end{array}$ \\
\hline & Média & 6.705 & 61,9 & - & - & $9,5 \mathrm{~A}$ & 9,8 \\
\hline \multirow[t]{2}{*}{ Uran } & $\begin{array}{l}\text { Superficial } \\
\text { Incorporada }\end{array}$ & $\begin{array}{l}7.575 \\
5.054\end{array}$ & $\begin{array}{l}72,7 \\
45,7\end{array}$ & $\begin{array}{l}0,725 \\
0,889\end{array}$ & $\begin{array}{r}7,2 \\
10,5\end{array}$ & $\begin{array}{l}5,2 \mathrm{a} \\
4,9 \mathrm{a}\end{array}$ & $\begin{array}{l}11,9 \\
11,2\end{array}$ \\
\hline & Média & 6.314 & 59,2 & - & - & $5,1 \mathrm{~B}$ & 11,6 \\
\hline DMS (entre fontes) & & $2.868^{\mathrm{ns}}$ & $24,0^{\text {ns }}$ & - & - & 3,2 & $7,1^{\mathrm{ns}}$ \\
\hline DMS (fonte $x$ fonte) & & $4.055^{\mathrm{ns}}$ & $33,9^{\text {ns }}$ & - & - & 4,5 & $10,1^{\mathrm{ns}}$ \\
\hline \multicolumn{8}{|c|}{ Grão } \\
\hline \multirow[t]{2}{*}{ U réia } & $\begin{array}{l}\text { Superficial } \\
\text { Incorporada }\end{array}$ & $\begin{array}{l}5.616 \\
6.096\end{array}$ & $\begin{array}{l}73,7 \mathrm{a} \\
82,6 \mathrm{a}\end{array}$ & $\begin{array}{l}1,154 \\
1,357\end{array}$ & $\begin{array}{l}15,9 \\
20,0\end{array}$ & $\begin{array}{l}11,7 \\
16,5\end{array}$ & $\begin{array}{l}12,2 \\
16,5\end{array}$ \\
\hline & Média & 5.856 & 78,2 & - & - & $14,2 \mathrm{~A}$ & 14,4 \\
\hline \multirow[t]{2}{*}{ Uran } & $\begin{array}{l}\text { Superficial } \\
\text { Incorporada }\end{array}$ & $\begin{array}{l}5.753 \\
4.621\end{array}$ & $\begin{array}{l}79,3 \mathrm{a} \\
59,9 \mathrm{~b}\end{array}$ & $\begin{array}{l}0,717 \\
0,889\end{array}$ & $\begin{array}{r}7,0 \\
10,5\end{array}$ & $\begin{array}{l}5,6 \\
6,3\end{array}$ & $\begin{array}{l}12,8 \\
14,4\end{array}$ \\
\hline & Média & 5.187 & 69,6 & - & - & $6,0 \mathrm{~B}$ & 13,6 \\
\hline DMS (entre fontes) & & $877^{\text {ns }}$ & $13,6^{\mathrm{ns}}$ & - & - & 4,4 & $5,7^{\mathrm{ns}}$ \\
\hline DMS (fonte $x$ fonte) & & $1.240^{\mathrm{ns}}$ & $19,2^{\text {ns }}$ & - & - & 6,2 & $8,1^{\text {ns }}$ \\
\hline \multicolumn{8}{|c|}{ Raiz } \\
\hline \multirow[t]{2}{*}{ U réia } & $\begin{array}{l}\text { Superficial } \\
\text { Incorporada }\end{array}$ & $\begin{array}{l}1.415 \\
1.162\end{array}$ & $\begin{array}{l}7,6 \\
7,4\end{array}$ & $\begin{array}{l}1,004 \\
1,231\end{array}$ & $\begin{array}{l}12,9 \\
13,3\end{array}$ & $\begin{array}{l}1,0 \\
1,0\end{array}$ & $\begin{array}{l}1,0 \\
1,0\end{array}$ \\
\hline & Média & 1.289 & 7,5 & - & - & 1,0 & 1,0 \\
\hline \multirow[t]{2}{*}{ Uran } & $\begin{array}{l}\text { Superficial } \\
\text { Incorporada }\end{array}$ & $\begin{array}{l}1.760 \\
1.157\end{array}$ & $\begin{array}{r}13,0 \\
7,1\end{array}$ & $\begin{array}{l}0,590 \\
0,778\end{array}$ & $\begin{array}{l}4,5 \\
8,3\end{array}$ & $\begin{array}{l}0,6 \\
0,6\end{array}$ & $\begin{array}{l}1,4 \\
1,4\end{array}$ \\
\hline & Média & 1.459 & 10,1 & - & - & 0,6 & 1,4 \\
\hline DMS (entre fontes) & & $1.171^{\mathrm{ns}}$ & $10,9^{\mathrm{ns}}$ & - & - & $1,0^{\text {ns }}$ & $1,6^{\text {ns }}$ \\
\hline DMS (fonte $x$ fonte) & & $1.656^{\mathrm{ns}}$ & $15,4^{\mathrm{ns}}$ & - & - & $1,4^{\text {ns }}$ & $2,3^{\text {ns }}$ \\
\hline \multicolumn{8}{|c|}{ Planta total } \\
\hline \multirow[t]{2}{*}{ U réia } & $\begin{array}{l}\text { Superficial } \\
\text { Incorporada }\end{array}$ & $\begin{array}{l}13.299 \\
14.401\end{array}$ & $\begin{array}{l}136,5 \\
158,7\end{array}$ & - & - & $\begin{array}{l}19,9 \mathrm{~b} \\
29,5 \mathrm{a}\end{array}$ & $\begin{array}{l}20,8 \\
29,5\end{array}$ \\
\hline & Média & 13.850 & 147,6 & - & - & $24,7 \mathrm{~A}$ & 25,2 \\
\hline \multirow[t]{2}{*}{ Uran } & $\begin{array}{l}\text { Superficial } \\
\text { Incorporada }\end{array}$ & $\begin{array}{l}15.088 \\
10.832\end{array}$ & $\begin{array}{l}165,0 \\
112,7\end{array}$ & - & - & $\begin{array}{l}11,4 \mathrm{a} \\
11,7 \mathrm{a}\end{array}$ & $\begin{array}{l}26,1 \\
26,8\end{array}$ \\
\hline & Média & 12.960 & 138,9 & - & - & $11,6 \mathrm{~B}$ & 26,5 \\
\hline DMS (entre fontes) & & $4.000^{\mathrm{ns}}$ & $41,1^{\mathrm{ns}}$ & - & - & 5,8 & $12,0^{\text {ns }}$ \\
\hline DMS (fonte $x$ fonte) & & $5.657^{\mathrm{ns}}$ & $58,1^{\mathrm{ns}}$ & - & - & 8,2 & $17,0^{\text {ns }}$ \\
\hline
\end{tabular}

(1) Médias seguidas por letras minúsculas diferentes, entre formas de aplicação para cada fonte, diferem entre si (Tukey 5\%). Médias seguidas por letras maiúsculas diferentes, entre fontes, diferem entre si (Tukey 5\%). Médias seguidas sem letras, entre fontes, não diferem entre si (Tukey 5\%). 


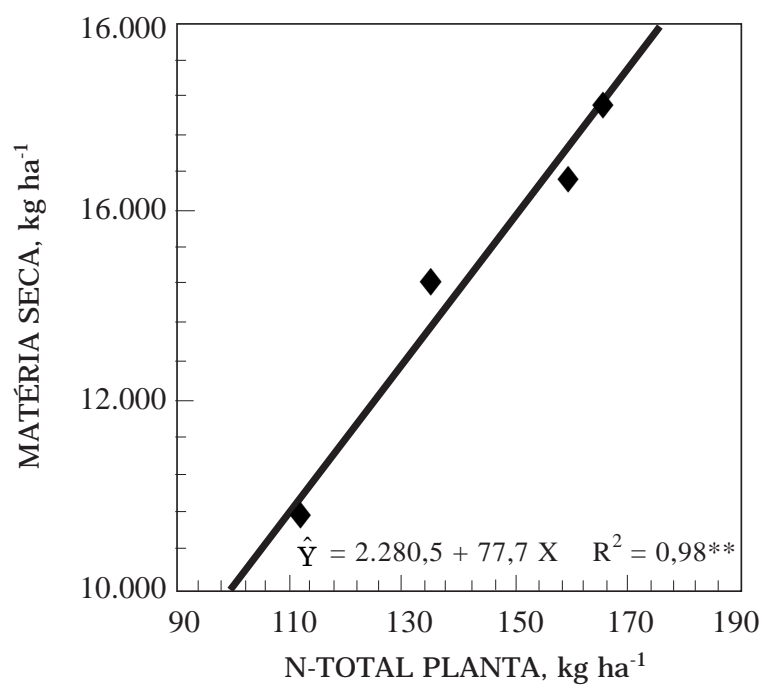

Figura 4. Efeito da absorção de $\mathrm{N}$-total na produção de matéria seca na cultura do mi lho em sistema plantio direto.

respectivamente, e de 0,94 kg ha-1, em média, para ambos os modos de aplicação do N-uréia do uran. O nitrogênio imobilizado do fertilizante (N ipf) foi a fração mais significativa do Ntpf até essa profundidade, correspondendo, em média, a 88,7\%, para ambos os modos de aplicação da uréia, ea 77,6\%, para o uran.
E mbora nãotenha havido diferença significativa entre os modos de aplicação com cada fonte (alta variação na média em virtude do baixo número de repetições), pode-se verificar que o $\mathrm{N}$-uréia do uran mostrou-se superior quando incorporado $\left(4,1 \mathrm{~kg} \mathrm{ha}^{-1}\right)$ em relação à aplicação superficial $(2,4$ kg ha-1). E ssa situação seria favorecida por duas características do uran em relação à uréia, a saber: a maior difusão no solo e a baixa incidência na variação do pH nolocal de aplicação (Trivelin et al. 1996), o que estaria favorecendo uma imobilização mais expressiva pela biomassa do solo. A uréia por sua vez, el eva o pH no local da aplicação (Trivelin et al., 1996; Rodrigues \& Kiehl, 1992), dificultando a imobilização temporária do $\mathrm{N}$-amoniacal produzido, o que favorece a nitrificação. Nesse caso, podeocorrer a lixiviação com o movimento descendente de água no perfil do solo e a desnitrificação pode ocorrer em condições anóxicas. A tendência a menores produtividades, sem considerar a testemunha $(6.262 \mathrm{~kg} \mathrm{ha}-1)$, poderia ser explicada quando a uréia foi aplicada na superfície (6.314 kg ha-1), em virtude da expressiva volatilização de $\mathrm{N}$-amoniacal e com a incorporação do uran (6.337 kg ha-1), fato atribuído, provavelmente, à ocorrência deimobilização durantea maior demanda pela cultura. Por sua vez, as maiores produtividades foram obtidas com a uréia incorporada $(6.645 \mathrm{~kg} \mathrm{ha}-1)$, em razão das reduzi das per das por volatilização com a incorporação do uran na superfície (6.844 kg ha-1),

Quadro 3. Nitrogênio total do solo (N-total), nitrogênio total do solo proveniente do fertilizante (Ntpf), nitrogênio mineral proveniente do fertilizante ( $\mathrm{Nmpf}$ ) e nitrogênio imobilizado proveniente do fertilizante (Nipf) nas camadas de 0-45 cm, após a aplicação superficial e incorporada da uréia e uran na cobertura nitrogenada de milho, em sistema plantio direto

\begin{tabular}{|c|c|c|c|c|c|c|c|c|}
\hline Tratamento & Profundidade & N-total & $\begin{array}{c}\text { Concentração } \\
\text { de }^{15} \mathbf{N}\end{array}$ & Ntpf & N-min total & $\begin{array}{c}\text { Concentração } \\
\text { de }{ }^{15} \mathbf{N}\end{array}$ & Nmpf & Nipf \\
\hline & $\mathrm{cm}$ & $\mathrm{kg} \mathrm{ha}^{-1}$ & Átom \% abun & \multicolumn{2}{|c|}{$\mathrm{kg} \mathrm{ha}^{-1} \ldots$} & Átom \% abun & \multicolumn{2}{|c|}{$\mathrm{kg} \mathrm{ha}^{-1} \_$} \\
\hline $\begin{array}{l}\text { Uréia } \\
\text { superficial }\end{array}$ & $\begin{array}{l}00-15 \\
15-30 \\
30-45 \\
\text { Total }\end{array}$ & $\begin{array}{l}1.995 \\
1.804 \\
1.229 \\
5.028\end{array}$ & $\begin{array}{l}0,396 \\
0,371 \\
0,370 \\
-\end{array}$ & $\begin{array}{r}10,37 \\
0,34 \\
0,17 \\
10,88\end{array}$ & $\begin{array}{l}13,2 \\
47,0 \\
17,8 \\
77,8\end{array}$ & $\begin{array}{l}- \\
- \\
- \\
0,411\end{array}$ & $\begin{array}{l}- \\
- \\
- \\
0,83\end{array}$ & $\begin{array}{c}- \\
- \\
- \\
10,05\end{array}$ \\
\hline $\begin{array}{l}\text { Uréia } \\
\text { incorporada }\end{array}$ & $\begin{array}{l}00-15 \\
15-30 \\
30-45 \\
\text { Total }\end{array}$ & $\begin{array}{l}2.094 \\
1.679 \\
1.114 \\
4.887\end{array}$ & $\begin{array}{l}0,390 \\
0,376 \\
0,375 \\
-\end{array}$ & $\begin{array}{r}8,37 \\
1,91 \\
1,03 \\
11,31\end{array}$ & $\begin{array}{r}7,1 \\
52,0 \\
24,0 \\
83,1\end{array}$ & $\begin{array}{l}- \\
- \\
- \\
0,452\end{array}$ & $\begin{array}{l}- \\
- \\
- \\
1,66\end{array}$ & $\begin{array}{l}- \\
- \\
- \\
9,65\end{array}$ \\
\hline $\begin{array}{l}\text { Uran } \\
\text { superficial }\end{array}$ & $\begin{array}{l}00-15 \\
15-30 \\
30-45 \\
\text { Total }\end{array}$ & $\begin{array}{l}2.070 \\
1.719 \\
1.186 \\
4.975\end{array}$ & $\begin{array}{l}0,377 \\
0,372 \\
0,369 \\
-\end{array}$ & $\begin{array}{l}2,31 \\
0,51 \\
0,00 \\
3,32\end{array}$ & $\begin{array}{l}10,3 \\
28,8 \\
29,7 \\
68,8\end{array}$ & $\begin{array}{l}- \\
- \\
- \\
0,416\end{array}$ & $\begin{array}{l}- \\
- \\
- \\
0,93\end{array}$ & $\begin{array}{l}- \\
- \\
- \\
2,39\end{array}$ \\
\hline $\begin{array}{l}\text { Uran } \\
\text { incorporado }\end{array}$ & $\begin{array}{l}00-15 \\
15-30 \\
30-45 \\
\text { Total }\end{array}$ & $\begin{array}{l}2.124 \\
1.518 \\
1.124 \\
4.766\end{array}$ & $\begin{array}{l}0,375 \\
0,376 \\
0,377 \\
-\end{array}$ & $\begin{array}{l}1,96 \\
1,53 \\
1,56 \\
5,05\end{array}$ & $\begin{array}{l}13,4 \\
44,7 \\
31,8 \\
89,9\end{array}$ & $\begin{array}{l}- \\
- \\
- \\
0,417\end{array}$ & $\begin{array}{l}- \\
- \\
- \\
0,95\end{array}$ & $\begin{array}{l}- \\
- \\
- \\
4,10\end{array}$ \\
\hline $\begin{array}{l}\text { MDS (entre tra } \\
\text { DMS (entre forn } \\
\text { DMS (entre forn }\end{array}$ & $\begin{array}{l}\text { tamentos) } \\
\text { nas dentro de uréia) } \\
\text { nas dentro do uran) }\end{array}$ & $\begin{array}{c}1.841^{\mathrm{ns}} \\
- \\
-\end{array}$ & $\begin{array}{l}- \\
- \\
-\end{array}$ & $\begin{array}{l}- \\
17,7^{\mathrm{ns}} \\
15,9^{\mathrm{ns}}\end{array}$ & $\begin{array}{l}59,3^{\text {ns }} \\
- \\
-\end{array}$ & $\begin{array}{l}- \\
- \\
-\end{array}$ & $\begin{array}{l}- \\
1,82^{\text {ns }} \\
1,69^{\text {ns }}\end{array}$ & $\begin{array}{l}- \\
16,83^{\text {ns }} \\
15,93^{\text {ns }}\end{array}$ \\
\hline
\end{tabular}


considerando provavelmente a volatilização pouco expressiva e reduzida imobilização do N-uréia.

\section{$\mathrm{N}$-mineral proveniente do fertilizante (N mpf) na profundidade de $45-150 \mathrm{~cm}$}

N esta seção do perfil, foram determinados o Nmineral total do solo e o Nmpf (Quadro 4), sendo desconsiderado o $\mathrm{N}$-imobilizado, porque a atividade microbiana do solo é maior na camada superficial (Doran, 1980a; Fernandes et al., 1998). No quadro 4, pode-se observar que o $\mathrm{N}$-mineral total sofreu um acréscimo marcante em profundidade (abaixo dos $90 \mathrm{~cm}$ ), muito provavel mente proveniente do Norgânico mineralizado elixiviado das camadas mais superficiais do solo, como assinalado por Coelho et al. (1991). As quantidades de $\mathrm{Nmpf}$ determinadas nesse perfil foram, em geral, pouco expressivas, sendo de 1,55 e 4,20, e 1,03 e 0,28\% do N-uréia aplicado em superfície eincorporado, das fontes uréia e uran, respectivamente. Essa baixa recuperação do $\mathrm{N}$-fertilizante no perfil poderia ser interpretada comolixiviação pou co expressiva, fenômeno também observado por Coel ho et al. (1991) e não coerente com o N-mineral total determinado. Em plantio direto, embora os processos oxidativos da matéria orgânica sejam mais lentos, em virtude do menor contato da palha em decomposição e da matéria microbiana, a adição deN-fertilizante, principalmente quando incorporado ao solo, estaria promovendo localmentea liberação do N-nativo (efeito "priming"), seguida da sua lixiviação, quando a pluviosidade supera a evapotranspiração (muito provável na época da aplicação da cobertura nitrogenada neste estudo), e pela maior ocorrência de macroporos na camada superficial do solo, como conseqüência do seu não-revolvimentonessesistema (Frye, 1984). Por outro lado, é questionável o procedimento utilizado neste estudo para a obtenção de amostras de solo em profundidade a fim de avaliar a lixiviação do Nfertilizante. Legg \& Meisinger (1982) assinalaram que, em microparcelas não confinadas (caso deste estudo), podem existir problemas de dispersão do fertilizante marcado, e mesmo com o confinamento dessas microparcelas existiria a possibilidade de haver drenagem lateral e subsuperficial que dificultaria uma amostragem representativa. Carter et al. (1967), citados por Legg \& Meisinger (1982),

Quadro 4. Nitrogênio mineral total e nitrogênio mineralizado proveniente do fertilizante (Nmpf) nas camadas de 45-150 cm de profundidade, após a aplicação superficial e incorporada de uréia e uran na cobertura nitrogenada em sistema plantio direto ${ }^{(1)}$

\begin{tabular}{|c|c|c|c|c|}
\hline Tratamento & Profundidade & N-min total & Concentração de ${ }^{15} \mathrm{~N}$ & Nmpf \\
\hline & $\mathrm{cm}$ & $\mathrm{kg} \mathrm{ha}^{-1}$ & Átom \% abun & kg ha-1 \\
\hline \multirow[t]{2}{*}{ Uréia superficial } & $\begin{array}{c}45-60 \\
60-90 \\
90-120 \\
120-150\end{array}$ & $\begin{array}{r}13,3 \\
104,0 \\
178,3 \\
160,9\end{array}$ & $\begin{array}{l}\ldots \\
\ldots \\
\ldots \\
\ldots\end{array}$ & $\begin{array}{l}\ldots \\
\ldots \\
\ldots \\
\ldots\end{array}$ \\
\hline & Total & $456,5 \mathrm{~A}$ & 0,386 & 1,48 \\
\hline \multirow[t]{2}{*}{ Uréia incorporada } & $\begin{array}{c}45-60 \\
60-90 \\
90-120 \\
120-150\end{array}$ & $\begin{array}{r}34,3 \\
26,8 \\
59,8 \\
108,7\end{array}$ & $\begin{array}{l}\ldots \\
\cdots \\
\cdots \\
\ldots\end{array}$ & $\begin{array}{l}\ldots \\
\ldots \\
\ldots \\
\ldots\end{array}$ \\
\hline & Total & 229,6 B & 0,460 & 4,20 \\
\hline \multirow[t]{2}{*}{ Uran superficial } & $\begin{array}{c}45-60 \\
60-90 \\
90-120 \\
120-150\end{array}$ & $\begin{array}{r}6,7 \\
46,4 \\
67,2 \\
100,6\end{array}$ & $\begin{array}{l}\cdots \\
\cdots \\
\cdots \\
\cdots\end{array}$ & $\begin{array}{l}\ldots \\
\ldots \\
\ldots \\
\ldots\end{array}$ \\
\hline & Total & $220,9 \mathrm{~B}$ & 0,380 & 0,45 \\
\hline \multirow[t]{2}{*}{ Uran incorporado } & $\begin{array}{c}45-60 \\
60-90 \\
90-120 \\
120-150\end{array}$ & $\begin{array}{r}20,5 \\
33,2 \\
115,1 \\
128,1\end{array}$ & $\begin{array}{l}\cdots \\
\cdots \\
\cdots \\
\cdots\end{array}$ & $\begin{array}{l}\cdots \\
\ldots \\
\ldots \\
\ldots\end{array}$ \\
\hline & Total & 296,9 AB & 0,372 & 0,12 \\
\hline DMS (entre tratamentos) & & 184,2 & - & - \\
\hline DMS (entre formas dentro de uréia) & & - & - & $3,27 \mathrm{~ns}$ \\
\hline DMS (entre formas dentro do uran) & & - & - & 0,39 ns \\
\hline
\end{tabular}

(1) Médias seguidas por letras maiúsculas diferentes, na coluna, entre tratamentos, diferem entre si (Tukey 5\%). 
mostraram que a sensibilidade na detecção do traçador foi afetada pelo método de amostragem do sol o. Quando efetuada a amostragem de todo o solo contido em lisímetros, com posterior subamostragem, houve uma recuperação de 98 a $101 \%$ do N aplicado. Entretanto, o método da amostragem composta (utilizado neste estudo) mostrou maior variação na recuperação: 86 a 137\%. Em condições de campo, portanto, as amostragens de solo em profundidade, visando à análise isotópica, devem ser refinadas.

\section{Balanço do N-uréia dos fertilizantes uréia e uran aplicados na superfície e incorporados no sistema solo - planta}

No quadro 5, consta o balanço do $\mathrm{N}$-uréia dos fertilizantes uréia e uran aplicados em superfície e incorporados. Nesse quadro, está incluído ointervalo de confiança das médias. Em geral, o balanço de $\mathrm{N}$ mostra que uma fração importante do N-uréia aplicado de ambas as fontes não foi recuperada. Tomando por base a quantidade de $\mathrm{N}$ aplicado em cada tratamento, em média, 13,4; 50,3; 20,8 e $25,1 \mathrm{~kg}$ ha-1 de $\mathrm{N}$ não foram recuperados da uréia aplicada na superfície e incorporada, e do uran aplicado na superfíciee incorporado, respectivamente. Os maiores intervalos de confiança foram obtidos com a aplicação superficial dos adubos, que levariam a fechar o bal anço se considerado o interval o superior decada fonte. Quando as fontes foram incorporadas, ainda considerando o intervalo superior, não se verificou o fechamento do balanço.

Neste estudo, o N não recuperado não pode ser atribuído às perdas por volatilização de amônia, visto que foram quantificadas, e estas poderiam até ser inferiores às registradas, se fosse quantificado o Namoniacal marcado, proveniente dos fertilizantes e retido nos coletores (Lara Cabezas et al., 1999). Portanto, as perdas mais prováveis seriam por desnitrificação e lixiviação. O acúmulo da matéria orgânica em plantio direto fornece o substrato energético necessário para o desenvolvimento da atividade microbiana (Doran 1980b), com o conseqüente consumo de $\mathrm{O}_{2}$ e aumento de sítios anaeróbios com a formação de $\mathrm{N}_{2} \mathrm{O}$ (Granli \& Bøckman, 1994). Burford et al. (1981) quantificaram emissões anuais de 5,4 a 8,6 kg ha-1 de $\mathrm{N}_{2} \mathrm{O}$ em plantio direto e de 0,9 a $5,6 \mathrm{~kg} \mathrm{ha}^{-1} \mathrm{deN}_{2} \mathrm{O}$ em plantio convencional. Na literatura, parece existir consenso geral de que as taxas de desnitrificação são superiores em solos com reduzida movimentação (Rice \& Smith, 1982; Linn \& Doran, 1984; Staley et al. 1990). Outros fatores que poderiam estar acentuando este processo nas condições deste estudo seriam a maior retenção de água no perfil associada à textura argilosa do solo (Amundson \& Davinson, 1990) e a compactação observada nas camadas de superfície com densidade do solo média de 1,32 a $1,34 \mathrm{~g} \mathrm{~cm}^{-3}$ nas camadas de 0-15 e 15-30 cm da área experimental. Em termos de lixiviação, o aumento de N-mineral total abaixo da camada de $90 \mathrm{~cm}$ evidencia a ocorrência desse processo, no qual o Nfertilizante deve estar envolvido.

\section{CONCLUSÕES}

1. Em ordem decrescente, as perdas de $\mathrm{N}-\mathrm{NH}_{3}$ volatilizado das fontes nitrogenadas de cobertura aplicadas em superfície foram: uréia = uréia + $\mathrm{KCl}>$ uran $=$ uran $+\mathrm{KCl}$. As perdas provenientes da uréia e do uran foram inferiores a $6 \%$ do $\mathrm{N}$ aplicado quando incorporadas a 5-7 cm de profundidade.

2. A eficiência do $\mathrm{N}$-uréia das fontes uréia e uran foi inferior a $30 \%$ do $\mathrm{N}$ aplicado, independentemente do modo de aplicação.

3. No perfil de $0-45 \mathrm{~cm}$ de profundidade no solo, independentemente do modo de aplicação das fontes nitrogenadas, o N-uréia imobilizado da uréia foi, em

Quadro 5. Balanço do Nitrogênio do fertilizante (Nrecf) no sistema solo - planta proveniente do fertilizante (Nppf), $\mathrm{N}$ na cobertura do solo (Ncobpf), $\mathrm{N}$ total proveniente do fertilizante até $45 \mathrm{~cm}$ de profundidade (Ntspf), $\mathbf{N}$ - mineral no solo da secção de $0-150 \mathrm{~cm}$ do perfil proveniente do fertilizante (Nmispf), $\mathbf{N}$ volatilizado do fertilizante (Nvpf) e N não quantificado

\begin{tabular}{|c|c|c|c|c|c|c|c|}
\hline Tratamento & Nppf & Ncobpf & Ntspf & Nmispf & Nvpf & Nrecf & N-não quantificado \\
\hline & & & & - kg ha & & & \\
\hline Uréia superficial & $19,9 \pm 12,2^{(1)}$ & $0,6^{(2)}$ & $10,9 \pm 25,8$ & $1,5 \pm 2,8$ & $49,4 \pm 9,7$ & $82,3 \pm 67,2$ & $13,4 \pm 67,2$ \\
\hline U réia incorporada & $29,5 \pm 3,2$ & $0,2 \pm 0,6$ & $11,3 \pm 5,4$ & $4,2 \pm 4,0$ & $4,6 \pm 1,2$ & $49,7 \pm 5,1$ & $50,3 \pm 5,1$ \\
\hline Uran superficial & $11,4 \pm 24,6$ & $0,2 \pm 0,2$ & $3,3 \pm 7,6$ & $0,4 \pm 0,6$ & $7,5 \pm 2,3$ & $22,8 \pm 25,2$ & $20,8 \pm 25,2$ \\
\hline Uran incorporado & $11,7 \pm 5,4$ & $11,7 \pm 5,4$ & $5,1 \pm 22,2$ & $0,1 \pm 0,1$ & $1,5 \pm 0,3$ & $18,5 \pm 16,3$ & $25,1 \pm 16,3$ \\
\hline
\end{tabular}

(1) Valor médio \pm intervalo de confiança (teste de $(0,90)$ ). ${ }^{(2)}$ Valor sem repetição. 
média, de $10,0 \%$ do $\mathrm{N}$ aplicado $(98,8 \mathrm{~kg}$ ha-1) e do Nuréia do uran foi de $7,6 \%(43,6 \mathrm{~kg}$ ha-1). No perfil de 0-150 cm, o N-mineral proveniente da uréia e do Nuréia do uran foi inferior a $6 \%$ do $\mathrm{N}$ aplicado, não sendo recuperada uma quantidade significativa do $\mathrm{N}$ dos fertilizantes.

\section{AGRADECIMENTOS}

A N ovartis-Seeds, pelo apoiologísticona instalação e manutenção experimental; aos alunos Dalton T. Shimada, Arnaldo . Alves e Aquiles Liberali, pela execução do trabal ho; ao CE NA/USP, Piracicaba (SP), pelas análises isotópicas realizadas; ao professor Gismar Silva Vieira, pela orientação nas análises estatísticas, à E mbrapa CN PMS-Sete Lagoas (MG), pelas análises foliares de $\mathrm{N}$ e $\mathrm{K}$, e às seguintes instituições: POTAFOS S.A., Piracicaba, SP; I pirangaSerrana Fertilizantes S.A., J aú, SP e Ultrafertil Fertilizantes, S.A., Cubatão(SP), peloapoio financeiro.

\section{LITERATURA CITADA}

AGROTAIN. Urease inhibitor. Product I nformation Guidebook, IMC-AGRICO, 1997. 43p.

ANJ OS, J.T. \& TEDESCO, M.J . Volatilização de amônia proveniente de dois fertilizantes nitrogenados aplicados em solos cultivados. Científica, 4:49-55, 1976.

AMUNDSON, R.G. \& DAVINSON, E.A. Carbon dioxide and nitrogenous gases in the soil atmosphere. J. Geochem. Explor., 38:13-41, 1990.

BROADBENT, F.E. \& CARLTON, A.B. Fields trials with isotopically labeled nitrogen fertilizer. In: NIELSEN, D.R. \& MAC DONALD, J .G., eds. Nitrogen in the environment. New York, Academic Press, 1978. p.1-41.

BULL, L.T. Nutrição mineral do milho. In: BULL, L.T. \& CANTARELLA, H., eds. Cultura do milho: fatores que afetam a produtividade. Piracicaba, Potafos, 1993. p.63-145.

BURFORD, J .R.; DOWDELL, R.J . \& CREES, R. Emissions of nitrous oxide to the atmosphere from direct-drilled and plouged clay soils. J . Sci. Food Agric., 32:219-223, 1981.

CALVACHE, M.; LIBARDI, P.L. \& REICHARDT, K. Utilização de nitrogênio fertilizante por dois híbridos de milho. Campinas, Fundação Cargill, 1982. 66p.

CANTARELLA, H. \& RAIJ , B. van. Adubação nitrogenada no Estado de São Paulo. In: SI MPÓSIO SOBRE ADUBAÇÃO NITROGENADA NO BRASIL, I Ihéus, 1985. Anais. Il héus, CEPLAC/Sociedade Brasileira de Ciência do Solo, 1985. p47-79.

COELHO, A.M.; FRANÇA, G.E. \& BAHIA, A.F.C. Balanço de nitrogênio $(15 \mathrm{~N})$ em um latossolo Vermelho-Escuro sob vegetação de cerrado, cultivado com milho. R. Bras. Ci. Solo, 15:187-193, 1991.
DORAN, J.W. Microbial changes associated with residues management with reduced tillage. Soil Sci. Soc. Am. J., 44:518-524, 1980a.

DORAN, J .W. Soil microbial and biochemical changes associated with reduced tilled. Soil Sci. Soc. Am. J ., 44:765-771, 1980b.

ERNST, J.W. \& MASSEY, H.F. The effects of several factors on volatilization of ammonia formed from urea in the soil. Soil Sci. Soc. Am. Proc., 24:87-90, 1960.

FAO/I AEA. Rice fertilization. Vienna, 1970a. (Technical Reports Series, 108)

FAO/IAEA. Fertilizer management practices for maize: Results of experiments with isotopes. Vienna, 1970b. (Technical Reports Series, 121)

FENN, L.B. O Potássio auxilia na redução das perdas de amônia no campo quando da aplicação superficial de uréia. Inf. Agron., 37:5-6, 1987.

FENN, L.B. \& KISSEL, D.E. The influence of cation exchange capacity and depth of incorporation on ammonia volatilization from ammonium compounds applied to calcareous soils. Soil Sci. Soc. Am. J ., 40:394-398, 1976.

FERNANDES, L.A.; FURTINI NETO, A.E.; VASCONCELLOS, C.A. \& GUEDES, G.A.A. Preparo do solo e adubação nitrogenada na produtividade do milho em latossolo sob vegetação de cerrado. R. Bras. Ci. Solo, 22:247-254, 1998.

FRIED, M.; SOPER, R.J . \& BROESHART, H. $15 \mathrm{~N}$-labelled singletreatment fertility experiments. Agron. J ., 67:393-396, 1975.

FRYE, W.W. Energy requirement in no-tillage. In: PHILLIPS, R.E. \& PHILLIPS, S.H., eds. No tillage agriculture. Principles and practices. New York, Reinhold, 1984. p.127230.

GRANLI, T. \& BØCKMAN, O.CHR. Nitrous oxide from agriculture. In: MAGRETE, W., ed. Agricultural University of Norway Publisher, 1994. 129p. Norwegian J . Agric. Sci. Supl. 12.

JENKINSON, D.S.; FOX, R.H. \& RAYNER, J.H. Interations between fertilizer nitrogen and soil nitrogen - so called “priming" effect. J .Soil Sci., 36:425-444, 1985.

KEENEY, D.R. \& NELSON, D.W. Nitrogen - inorganic forms. In: PAGE , A.L.; MILLER, R,H. \& KEENEY, D.R., eds. Methods of soil analysis. Part 2. Chemical and microbiological properties. 2.ed. Madison, American Society of Agronomy, 1982. p.687-693. (Agronomy, 9)

KITUR, B.K.; SMITH, M.S.; BLEVINS, R.L. \& FRYE, W.W. Fate of $15 \mathrm{~N}$-depleted ammonium nitrate applied to no-tillage and conventional tillage corn. Agron. J ., 76:240-242, 1984.

LARA CABEZAS, W.A.R.; KORNDÖRFER, G.H. \& MOTTA, S.A. Volatilização de $\mathrm{N}-\mathrm{NH}_{3}$ na cultura de milho: I Efeito da irrigação e substituição parcial da uréia por sulfato de amônio. R. Bras. Ci. Solo, 21:481-487, 1997a.

LARA CABEZAS, W.A.R.; KORNDÖRFER, G.H. \& MOTTA, S.A. Volatilização de $\mathrm{N}-\mathrm{NH}_{3}$ na cultura de milho: Il Avaliação de fontes sólidas e fluidas em sistema plantio direto e convencional. R. Bras. Ci. Solo, 21:489-496, 1997b.

LARA CABEZAS, W.A.R.; TRIVELIN, P.C.O.; BENDASSOLLI, J .A.; SANTANA, D.G. \& GASCHO, G.J . Calibration of a semi-open static collector for determination of ammonia volatilization from nitrogen fertilizers. Comm. Soil Sci. Plant Anal., 30:389-406, 1999. 
LATKOVICZ, I.; MATE, F . \& VARGA, D. Rol of nitrogen in mineral fertilizer in maize growth studied with the aid of labelled $15 \mathrm{~N}$. In: IAEA. I sotopes studies on the nitrogen chain. Vienna, 1968. p.109.

LINN, D.M. \& DORAN, J .W. Effect of water - filled pore space on carbon dioxide and nitrous oxide production in tilled and nontilled soils. Soil Sci. Soc. Am. J ., 48: 1267-1272, 1984.

LEGG, J.O. \& MEISINGER, J J . Soil nitrogen budgets. In: STEVENSON, F.J ., ed. Nitrogen in agricultural soils. Madison, American Society of Agronomy, 1982. p.503-566. (Agronomy, 22)

LOVELL, R.D. \& HATCH, D.J . Stimulation of microbial activity spring applications of nitrogen. Biol. Fertil. Soils, 26:28-30, 1998.

MCGILL, W.B. \& FIGUEIREDO, C.T. Total nitrogen. In: CARTER, M.R., ed. Boca Raton, Lewis Publishers, 1993. p.201-211.

MELLO, F.A.F.; ARZOLLA, S. \& KIEHL, J .C. Efeito de doses e modos de aplicação de uréia na produção de milho. R. Bras. Ci. Solo, 12:269-274, 1988.

NOMMIK, H. The effect of pellet size on the ammonia loss from urea applied to forest soil. Plant Soil, 39:309-318, 1973.

OLSON, R.V. Fate of tagged nitrogen fertilizer applied to irrigated corn. Soil Sci. Soc. Am. J ., 44:514-517, 1980.

OLSON, R.A. \& KURTZ, L.T. Crop nitrogen requirements, utilization and fertilization. In: STEVENSON, F.J ., ed. Nitrogen in agricultural soils. Madison, American Society of Agronomy, 1982. p.567-604 (Agronomy, 22)

OVERREIN, L.N. \& MOE, P.G. Factors affecting urea hidrolysis and ammonia volatilization in soil. Soil Sci. Soc. Am. Proc., 31:57-61, 1967.

PARKINSON, J.A \& ALLEN, S.E. A wet oxidation procedure suitable for the determination nitrogen and mineral nutrients in biological material. Comm. Soil Sci. Plant Anal., 6:1-11, 1975.

PRASAD, M. Gaseous loss of ammonia from sulfur-coated urea, ammonium sulfate, and urea applied to calcareous soil (pH 7.3). Soil Sci. Soc. Am. J ., 40:130-134, 1976.

RAO, A.C.S.; SMITH, J .F.; PARR, J .F. \& PAPENDICK, R.I. Considerations in estimating nitrogen recovery efficiency by the difference and isotope methods. Fert. Res., 33:209217, 1992.

REDDY, G.B. \& REDDY, K.R. Fate of nitrogen-15 enriched ammonium nitrate applied to corn. Soil Sci. Soc. Am. J ., 57:111-115, 1993.
RICE, C.W. \& SMITH, M.S. Denitrification in plowed and no-till soils. Soil Sci. Soc. Am. J ., 46:1168-1173, 1982.

RODRIGUES, M.B.\& KIEHL, J.C. Distribuição enitrificação da amônia proveniente da uréia aplicada ao solo. R. Bras. Ci. Solo, 16:403-408, 1992.

SÁ, J .C.M. Reciclagem de nutrientes dos resíduos culturais, e estratégia de fertilização para produção de grãos no sistema plantio direto. In: SEMINÁRIO SOBRE O SISTEMA PLANTIO DIRETO NA UFV, 1., Viçosa, 1998. Resumos de palestras. Viçosa, 1998. p.19-61.

SANCHEZ, C.A. \& BLACKMER, A.M. Recovery of anydrous ammonia-derived nitrogen-15 during three years of corn production in I owa. Agron. J ., 80:102-108, 1988.

STALEY,T.E.; CASKEY, W.H.\& BOYER, D.G. Soil denitrification and nitrification potentials during the growing season relativeto tillage. Soil Sci. Soc. Am. J ., 54:1602-1608, 1990.

TRANI, P.E.; HIROCE, R. \& BATAGLIA, O.C. Análise foliar, amostragem e interpretação. Campinas, Fundação Cargill, 1983. $18 p$

TRIVELIN, P.C.O.; SALATI, E. \& MATSUI, E. Preparo de amostras para análise de ${ }^{15} \mathrm{~N}$ por espectrometria de massas. BT-002, Piracicaba, CENA, 1973. 41p.

TRIVELIN, P.C.O.; STEFFANUTI, R.; LIMA FILHO, O.F.; TZIBOY, A.; OLIVEIRA J UNIOR, A. \& A. BENDASSOLLI, J .A. Volatilização de amônia do solo associada à aplicação superficial de solução nitrogenada com uréia e nitrato de amônio. In: CONGRESSO LATINOAMERICANO DE CIÊNCIA DO SOLO, 13., 1996. Águas de Lindoia. 1996 Solo - Suel o 96: Trabalhos... Piracicaba, Sociedade Brasileira de Ciência do Solo, 1996. CD ROM.

TSAI, C.Y.; STROMBERGER, J .A; DWEIKAT, I.M. \& HUBER, D.M. Interations of maize genotypes with ammonium nutrition. In: PROCEEDINGS OF A SYMPOSIUM EFFECTS OF ENHANCED AMMONIUM DIETS ON GROWTH AND YIELD OF WHEAT AND CORN, Denver, Colorado, 1991. Proceedings. Denver, Colorado, Soil Science Society of American,1991. p.70-79.

VLEK, P.L. \& STUMPE, J.M. Effect of solution chemistry and environmental conditions on ammonia volatilization losses from aqueous systems. Soil Sci. Soc. Am. J ., 42:416-421, 1978.

WESTERMAN, R.L. \& KURTZ, L.T. I sotopic and non-isotopic estimations of fertlizers nitrogen uptake by Sudan grass. Soil Sci. Soc. Am. Proc., 38:107-109, 1974.

YAMADA, T. Adubação nitrogenada do milho. Quanto, como e quanto aplicar? Inf. Agron., 74:1-5, 1996. 